\title{
Los avisos clasificados en la Gaceta de Cartagena de Colombia, 1822-1825: anuncios en una ciudad en proceso de recuperación
}

\author{
Roger Pita Pico \\ Academia Colombiana de Historia \\ rogpitc@hotmail.com
}

Recibido: septiembre 2015

Aprobado: diciembre 2015

Resumen: El propósito de este trabajo consiste en abordar las características, el alcance y el impacto de los avisos clasificados publicados en la Gaceta de Cartagena de Colombia en el periodo comprendido entre 1822 y 1825. Estos anuncios impresos se convirtieron en un nuevo espacio de difusión para aquellos interesados en llevar un mensaje a la comunidad, ya fuera a manera de información, servicio social o promoción de oportunidades económicas. El contenido mismo de los avisos publicados en estos primeros años de vida republicana reflejó de distintas formas los efectos de las guerras de Independencia y el periodo de transición al sistema republicano. Quedó además demostrado a través de estos anuncios el carácter cosmopolita de la ciudad en su calidad de puerto marítimo con una intensa actividad comercial y una importante participación de comerciantes extranjeros.

Palabras claves: prensa, avisos clasificados, información, Cartagena, República, siglo XIX.

\section{Classified ads in the Gaceta de Cartagena de Colombia, 1822-1825: ads in a city in recovery process}

Abstract: The purpose of this paper is to analyze the nature, scope and impact of classified ads published in the Gaceta de Cartagena de Colombia in the period between 1822 and 1825. These print ads became a new space to spread out a message to the

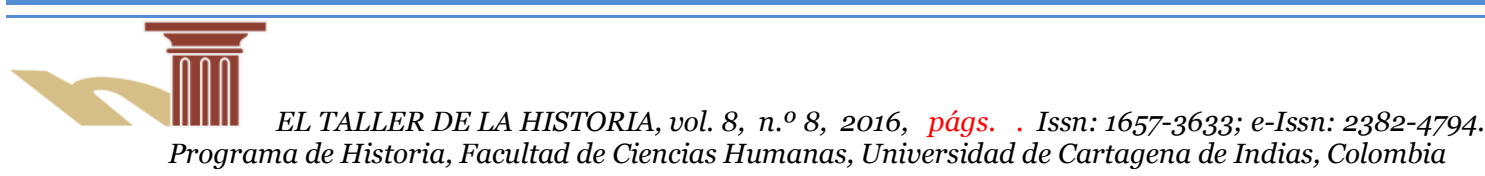


community, either as way of information, social service and promotion of economic opportunities. The content of ads published in these first years of republican life in different ways reflected the effects of the wars of Independence and the period of transition to republican system. It was demonstrated through these ads the cosmopolitan character of the city in his capacity seaport with intense commercial activity and a significant influence of foreign merchants.

Key words: newspapers, classifieds ads, information, Cartagena, Republic, nineteenth century.

\section{Presentación}

A finales del siglo XVIII se marcan los inicios de la prensa en el territorio neogranadino en medio de no pocas dificultades. Para antes de 1810 se habían fundado en Santa Fe no más de 10 periódicos. El desarrollo de este sector a nivel provincial fue más tardío. Hacia 1794 llegó a Cartagena la primera imprenta oficial, gracias a las gestiones adelantadas por el Real Consulado de Comercio y, entre 1808 y 1810, se editó el primer periódico en esta ciudad bajo el título de Noticias Públicas de Cartagena de Indias $^{1}$.

Desde la Primera República Federativa se hizo evidente el auge de la prensa en el antiguo territorio neogranadino, principalmente en la capital Santa Fe y a nivel provincial en Cartagena. Durante estos años fueron fundados en esta ciudad costera los siguientes periódicos: la Gazeta de Cartagena de Indias, El Argos Americano, Década: miscelánea de Cartagena, El Efímero de Cartagena, El Observador colombiano, El Mensagero de Cartagena de Indias y El Curioso de Cartagena, los cuales se convirtieron en un espacio propicio para el intenso debate político que se vivía por estos años en torno a temáticas como el modelo de gobierno o el grado de independencia frente a España.

Durante la etapa de Reconquista, las autoridades españolas vieron la necesidad de contar en la ciudad con un medio de comunicación y por ello crearon la Gaceta del Gobierno de Cartagena de Indias y la Gaceta Real de Cartagena de Indias. A finales

${ }^{1}$ Renán Silva Olarte, "El periodismo y la prensa a finales del siglo XVIII y principios del siglo XIX en Colombia”, Cali, Documento CIDSE Universidad del Valle, 2003, pp. 14-20. 
de 1821, luego de una alta cuota de sacrificio, Cartagena fue recuperada definitivamente por las huestes patriotas. Tras la guerra, la ciudad había perdido su importancia geopolítica, su economía estaba devastada mientras que sus habitantes y clase dirigente registraban una ostensible merma².

Paulatinamente, la sociedad cartagenera fue retomando su ritmo de vida de acuerdo a los parámetros fijados por el régimen republicano y el 16 de febrero de 1822 sale a la luz pública un nuevo esfuerzo periodístico: la Gaceta de Cartagena de Colombia. Esta sería apenas la primera de otras iniciativas como: La Reforma (1823), Correo del Magdalena (1825), Cometa Mercantil (1826), El Mundo Observador (1826), El Arlequín Cartagenero (1826) y La Aurora de Colombia (1827), las cuales brindarían a nivel local y provincial una voz de opinión durante esta segunda fase republicana3.

En la oleada de periódicos fundados en la segunda década del siglo XIX fue en realidad muy escasa la publicación de anuncios o clasificados, los cuales adquirieron un mayor auge en los impresos creados a partir de 1822. Los avisos eran anuncios cortos con información precisa y por lo general aparecían al final de la última página del periódico, a veces diferenciados con otro tipo o tamaño de letra. En esta sección solía insertarse también una fe de erratas con las equivocaciones tipográficas de la edición anterior.

Es posible que por su postrera ubicación estos avisos pudieran pasar desapercibidos para algunos lectores. No obstante, esta sección se constituyó en una fuente de información valiosa o, en otros casos, en una oportunidad de inversión económica.

El análisis político es el que ha primado en los estudios historiográficos de la prensa en Colombia, siendo en realidad muy pocos los investigadores que se han interesado en los periódicos a escala regional. Así entonces, este artículo tiene como objeto examinar las características, el alcance y el impacto de los avisos clasificados publicados en la Gaceta de Cartagena de Colombia en el periodo comprendido entre 1822 y 1825 . La muestra abarca un total de 431 avisos publicados desde el primer número hasta la edi-

\footnotetext{
${ }^{2}$ Adelaida Sourdís de Najera, "Cartagena de Indias, visión panorámica”, en: Credencial Historia, No. 222, Bogotá, Revista Credencial, junio de 2008, p. 5.

3 Sobre esta oleada de periódicos, véase: Nataly Polo Barros, La prensa en Cartagena: algunos aspectos sobre Nación 1820-1840, Cartagena, Tesis de Grado del programa de Historia de la Universidad de Cartagena, 2015, pp. 26-44.
} 
ción No. 228. Estos anuncios hacían referencia principalmente a informaciones, ofertas y servicios en la ciudad de Cartagena aunque en varios casos estaban dirigidos al vasto territorio regional que le circundaba. Asimismo, circularon algunos mensajes de carácter nacional que el gobierno central buscaba difundir a través de las gacetas regionales y otros cuantos avisos informativos procedentes de gobiernos provinciales aledaños.

De acuerdo a la necesidad o urgencia del responsable del anuncio, era usual que la misma nota saliera en dos o más ediciones. También solía suceder que una misma persona o entidad optara por colocar un aviso de manera simultánea en la Gaceta de Cartagena de Colombia y en otro periódico en circulación, como fue el caso del semanario Correo del Magdalena.

Por ser Cartagena una ciudad que congregaba a una gran cantidad de extranjeros, en algunas ocasiones el aviso era publicado no solo en español sino en otras lenguas como el inglés y el francés, ejemplo de lo cual fue la convocatoria abierta por la escuela de primeras letras instalada por Andrés Ballon 4 o aquel en el que se informaba sobre la inauguración de un café billar ubicado en la plaza de mercado de la ciudad5.

\section{Los avatares administrativos}

A través de los mismos avisos de la Gaceta ${ }^{6}$, es posible rastrear las vicisitudes administrativas y las peripecias que debieron superarse con tal de mantener activa esta publicación. El periódico era vendido al detal o a través del sistema de suscripción, caso este en el cual se informaba anticipadamente a los abonados por medio de avisos sobre el inicio y fin de cada trimestre de afiliación.

\footnotetext{
4 “Aviso", en: Gaceta de Cartagena de Colombia, No. 191, Cartagena, Imprenta del Gobierno por Juan Antonio Calvo, abril 9 de 1825, p. 4.

5 “Aviso", en: Gaceta de Cartagena de Colombia, No. 213, septiembre 17 de 1825, p. 4.

${ }^{6}$ En adelante se utiliza esta versión abreviada cuando se hace referencia a la Gaceta de Cartagena de Colombia.
} 
Debido a los múltiples trabajos que debía evacuar la imprenta7 $\mathrm{y}$, a la poca cantidad de tipos disponibles, se anunció en agosto de 1823 que el periódico ya no circularía dos veces a la semana sino únicamente cada sábado. Otra noticia desalentadora para los seguidores de este medio impreso era que en adelante el valor de la suscripción semestral no podía ser inferior a 3 pesos debido al aumento en el precio del papel y demás gastos de funcionamiento ${ }^{8}$.

En agosto de 1825 se anunció al público el cambio de editores pero haciendo la aclaración de que los antiguos dueños quedaban a cargo del empréstito que se había diligenciado para el sostenimiento de este negocio. Igualmente se aprovechó este aviso para solicitar los servicios de dos oficiales de caja para trabajar en la imprenta del periódi$\mathrm{co}^{9}$.

Con el fin de dar un verdadero impulso a la prensa durante estos años iniciales de vida republicana, los encargados de la Gaceta se interesaron en apoyar el surgimiento de otros periódicos, bajo la convicción de que esto redundaría en beneficio del progreso educativo y cultural de los cartageneros. Así entonces, se empezaba a perfilar una activa solidaridad en este incipiente gremio periodístico con el fin de fortalecerlo.

Con el lema: "La ilustración pública es la base de todo gobierno popular", la Gaceta pregonó en mayo de 1822 con gran complacencia la puesta en circulación de un nuevo periódico en la ciudad: El Calamar, noticioso, mercantil, político y literario. Este semanario tendría un formato de medio pliego de papel y su precio de venta por unidad sería de medio real mientras que para los suscriptores el costo especial era de tres pesos por semestre. Los editorialistas de la Gaceta invitaron a sus lectores a contribuir al sostenimiento de este nuevo medio de comunicación a través de la compra de suscripciones en la imprenta y en la tienda del señor Zubiandi en la calle de las Carretas ${ }^{10}$.

$\mathrm{Al}$ cabo de tres meses, la Gaceta anunció la creación de un nuevo periódico en la ciudad de Bogotá: La Indicación. Se hizo un llamado especial a los cartageneros para que

7 No hay que olvidar que la misma imprenta de la Gaceta ofrecía a través de este mismo medio sus servicios particulares al público.

${ }^{8}$ Gaceta de Cartagena de Colombia, No. 105, agosto 16 de 1823, p. 438.

9 “Aviso", en: Gaceta de Cartagena de Colombia, No. 210, agosto 27 de 1825, p. 4.

10 “Otro", en: Gaceta de Cartagena de Colombia, No. 13, mayo 11 de 1822, p. 58. 
apoyaran este nuevo medio escrito, cuyos primeros números, según se dijo, cumplían "laudables" fines de control a la gestión pública y al cumplimiento de la Constitución y de las leyes. Se ofreció la posibilidad de suscripción con el pago de dos pesos semestrales, para lo cual los interesados debían enviar sus datos e información del domicilio personal al ciudadano Manuel Ricaurte ${ }^{11}$. Para el lunes 28 de julio de 1823 se anunció la puesta en circulación de El Justiciero Cartagenero, cuya suscripción sería de 12 reales por trimestre con pago anticipado y con el beneficio de que los abonados recibirían el periódico en sus respectivas casas ${ }^{12}$.

A principios de mayo de 1825, la Gaceta informó sobre la aparición de un nuevo periódico en Cartagena titulado Correo del Magdalena, el cual circularía el jueves de cada semana. Los editores de este impreso se comprometieron a trabajar en "la propagación de los conocimientos útiles y conducentes a la consolidación de las instituciones tutelares de Colombia", con artículos dedicados a promover la educación pública, la agricultura, el comercio y la industria nacional. Por otro lado, se expresó el vivo interés de vigilar la conducta y accionar de los empleados oficiales. Los artículos podían ser enviados a la sede del impresor Juan Antonio Calvo en donde además podían diligenciarse las suscripciones a 12 reales por trimestre ${ }^{13}$.

Con gran satisfacción se dieron a conocer también las novedades de la prensa internacional. Un aviso que apareció en la Gaceta en octubre de 1823 anunció la publicación de los primeros números del Hurón y La Urraca ${ }^{14}$. No hay que olvidar que en el periódico solía observarse un gran despliegue a las noticias externas y tampoco era extraño encontrar la reproducción completa de artículos de periódicos producidos en Europa y Estados Unidos.

\section{Avisos oficiales}

Sin duda, uno de los mayores promotores de los avisos de prensa fue el gobierno nacional, provincial y local. Esto no era un hecho fortuito sino que respondía al afán que

\footnotetext{
11 "La Indicación”, en: Gaceta de Cartagena de Colombia, No. 28, agosto 24 de 1822, p. 122. 12 "El Justiciero Cartagenero", en: Gaceta de Cartagena de Colombia, No. 99, julio 23 de 1823, p. 414. 13 “Aviso", en: Gaceta de Cartagena de Colombia, No. 195, mayo 7 de 1825, p. 4. 14 “Aviso", en: Gaceta de Cartagena de Colombia, No. 116, noviembre $1^{\circ}$ de 1823, p. 482.
} 
tenía el naciente Estado republicano de organizar y ajustar su andamiaje administrativo de acuerdo al nuevo régimen político.

Entre los muchos avisos de este tipo, figuraban aspectos como la noticia sobre el restablecimiento de la venduta pública, el reporte de créditos contra la hacienda pública, el establecimiento del impuesto a los pulperos y el gravamen a los vendedores de aguardiente. En otro aviso de carácter nacional, el vicepresidente Francisco de Paula Santander informó que se expedirían letras de cambio contra el agente residente en Londres, encargado de tramitar un empréstito para Colombia ${ }^{15}$.

La reestructuración del servicio oficial de correos bajo el régimen republicano ameritó también algunos anuncios informativos. El general Rafael Urdaneta, intendente y comandante general del departamento del Zulia, informó en agosto de 1824 sobre la puesta en funcionamiento de dos rutas mensuales de Maracaibo a Riohacha pasando por la Guajira, las cuales debían salir el 8 y el 23 de cada mes ${ }^{16}$. A los pocos días, se anunció que el $1^{\circ}$ y el 15 de cada mes saldría el correo de Cartagena al istmo de Panamá. En octubre del año siguiente, el administrador general de Correos del departamento del Magdalena suplicó a los estafetas dar razón de una carta dirigida al señor Pedro Díaz Granados de la ciudad de Santa Marta, documento que aún no había llegado a su destino junto con algunos papeles referentes a un crédito público ${ }^{17}$.

Por esta época fue una preocupación del Estado republicano conseguir el personal idóneo para desempeñar cargos en procura de la buena marcha de la gestión pública y, en respuesta a ello, se abrieron convocatorias públicas a través de la prensa. En marzo de 1823 se comunicó a la ciudadanía que se hallaba vacante el empleo de contador general decano de la República. Las hojas de vida debían enviarse a la secretaría de Es$\operatorname{tado}^{18}$. A mediados de 1825 el intendente departamental convocó a candidatos interesados para el empleo de archivero con sueldo de 500 pesos mensuales ${ }^{19}$. No habiendo el número suficiente de cirujanos y practicantes que el reglamento estipulaba para el

\footnotetext{
15 "Aviso oficial”, en: Gaceta de Cartagena de Colombia, No. 150, junio 26 de 1824, p. 628.

16 "Aviso", en: Gaceta de Cartagena de Colombia, No. 157, agosto 14 de 1824, p. 4.

17 “Aviso”, en: Gaceta de Cartagena de Colombia, No. 219, octubre 29 de 1825, p. 4.

18 “Aviso", en: Gaceta de Cartagena de Colombia, No. 64, marzo 22 de 1823, p. 274.

19 “Aviso", en: Gaceta de Cartagena de Colombia, No. 200, junio 11 de 1825, p. 4.
} 
normal funcionamiento del hospital militar de esta plaza, el intendente invitó a los que se consideraran idóneos a presentarse en la oficina de la secretaría para llenar las vacantes disponibles ${ }^{20}$.

El mecanismo de convocatoria pública a través de la prensa también se utilizó para prestar servicios al Estado, especialmente para el estamento militar que por esta época seguía aún en máxima alerta para preservar la libertad alcanzada. En agosto de 1823, un aviso dio cuenta del interés oficial de requerir los servicios de cinco sastres para elaborar uniformes militares y de la marina, con el incentivo de que serían "bien pagados y constantemente empleados" 21 . En octubre de 1825, el comandante general de Cartagena avisó sobre el fenecimiento del contrato de suministro de raciones para los buques de guerra y, en consecuencia, abrió una nueva convocatoria con la condición de que cada ración ordinaria debía componerse de: cuatro onzas de arroz o fríjoles, media libra de galleta en el mar o de pan fresco en el puerto, una libra de carne salada de vaca o de puerco, media libra de papa o ñame, un quinto de botella de ron, media libra de carbón, un décimo de botella de vinagre, una onza de café o cacao triturado y una onza de azúcar prieta ${ }^{22}$.

En julio de 1824 el comandante general del departamento del Magdalena elevó un llamado al señor James Osle May para notificarlo de la resolución del gobierno supremo en la que se aceptaba su solicitud de incorporación al servicio militar de la República. Al año siguiente, se convocó a los jóvenes que quisieran servir en la marina para que concursaran por tres cupos en la escuela náutica, con el fin de reemplazar a tres graduados que ya se habían embarcado en buques de guerra ${ }^{23}$.

La salud pública fue otra de las preocupaciones del gobierno republicano y en especial las campañas de vacunación para neutralizar las epidemias. El regidor encargado de la sanidad de Cartagena, Tomás de Gordon, anunció el 22 de mayo de 1824 que ya se hallaba disponible la vacuna contra la viruela que se había asomado a la ciudad causando bastantes estragos. El lunes 24 todos los adultos y párvulos interesados en ser

\footnotetext{
20 “Aviso oficial”, en: Gaceta de Cartagena de Colombia, No. 195, mayo 7 de 1825, p. 4.

21 “Aviso", en: Gaceta de Cartagena de Colombia, No. 103, agosto 6 de 1823, p. 430.

22 "Otro", en: Gaceta de Cartagena de Colombia, No. 218, octubre 22 de 1825, p. 4.

${ }_{23}$ Gaceta de Cartagena de Colombia, No. 152, julio 10 de 1824, p. 641.
} 
inoculados debían acudir a la sede de la extinta Inquisición, ubicada al frente de la casa del ciudadano Francisco Paniza. Los cantones de esta y de cualquier otra provincia podían también acceder a la vacuna, previa solicitud 24 . Para los días 4, 14 y 24 de julio se organizó una jornada de vacunación en la casa del médico de sanidad Ignacio Carreño en la esquina de Santa Teresa ${ }^{25}$.

Tal como lo reportó a través de un aviso la policía de sanidad, el día 22 de mayo de 1825 a la ciudad de Cartagena entró la goleta nacional Gran María procedente de Kingston con algunas dosis de vacunas. Se instó a las autoridades locales y a la intendencia para que aunaran esfuerzos con miras a expandir este beneficio no solo a la ciudad sino también a Santa Marta, Mompós, Riohacha y otras poblaciones de la región Caribe ${ }^{26}$.

\section{Inversiones comerciales y cuentas claras}

La prensa cumplió un papel importante en la divulgación de las ideas propias del sistema capitalista ligadas al consumismo, hecho que estaba enmarcado en el proceso embrionario del libre comercio y la formación de un mercado nacional27.

Tiendas, almacenes y firmas comerciales extranjeras eran por esta época un componente esencial de la vida urbana de Cartagena y en esos espacios se ofrecía una variedad de productos, muchos de ellos importados. Este tipo de avisos nos permite asomarnos a las prácticas de consumo y a la vida material de las familias cartageneras, especialmente aquellas de más alto rango social y económico que eran las que contaban con mayor poder adquisitivo. Entre la gama de mercancías, sobresalían las telas, los adornos y los vinos. Muchos de estos productos eran comercializados en el interior de Colombia.

\footnotetext{
24 "Vacuna", en: Gaceta de Cartagena de Colombia, No. 145, mayo 22 de 1824, p. 608.

25 "Vacuna", en: Gaceta de Cartagena de Colombia, No. 151, julio 3 de 1824, p. 628.

26 “Aviso", en: Gaceta de Cartagena de Colombia, No. 198, mayo 28 de 1825, p. 4.

${ }_{27}$ María Carolina Cubillos Vergara, "El difícil tránsito hacia la modernidad: la prensa en Colombia”, en Folios, No. 27, Medellín, Universidad de Antioquia, 2012, p. 49.
} 
A partir de 1824 fue cada vez más frecuente encontrar en la Gaceta este tipo de avisos promocionales. La firma Duncan, Aldane y Cía. anunció a finales de noviembre la venta de varios productos a "precios equitativos": coletas, brines, platillas de hilo, pañuelos, muselinas, calicoes, percales, Irlandas de algodón, zarazas, tercerolas con copas, copitas de cinta, guardabrisas y fruteras, entre otros ${ }^{28}$.

En ese mismo mes el comerciante Santiago Brush ofreció a sus potenciales clientes los siguientes productos exhibidos en su almacén: platillas blancas, estopillas, paños de la Reina, mahones azules, jabón de Castilla, cera blanca, papel, naipes españoles, te en cajas de seis libras, café, tabaco, comino, aceite de comer en botijuela, aguardiente de España, vino catalán en barriles, vino seco, vino muscat, vino tinto francés, etc ${ }^{29}$.

En diciembre el comerciante Pedro Mustiere anunció que en el entresuelo de la casa del señor del Valle, ubicada en la calle de las Carretas, comercializaba a "precios moderados" cintas de seda, gaza para trajes de baile, blondas, pañuelitos de punto, velos y cordones de seda ${ }^{30}$.

También por esos días, la firma Still, M. Farlane y Cía. anunció en venta las siguientes mercancías: bretañas finas y ordinarias, fulas blancas, mantas de lana, cotines y nanquines, mahones azules y amarillos, zarazas para colchas, medias de seda, muselinas labradas, hilo, pañuelos de seda, sillas de montar, estuches de baúles, sombreros, zapatos, botas, caserillos, periódicos, canela, jabón de resina y de la India, nuez moscada, jamones de Westphalia, losa, cristales, cerveza, ron, vino de madera en pipas, vino francés, pintura de varios colores en barrilitos, aceite de linaza, machetes, planchas y clavos de cobre, alambre y clavos de hierro, hachuelas, azadas, quinquillería, alfileres, talco y cajoncito de hojas de lata ${ }^{31}$.

Por otro lado, través de atractivos mensajes, los dueños de establecimientos públicos buscaron la forma de lograr mayor afluencia en sus negocios, los cuales a su vez contribuían a dinamizar la vida social de la ciudad. Calixto Noguera anunció en septiem-

\footnotetext{
28 "Aviso", en: Gaceta de Cartagena de Colombia, No. 170, noviembre 13 de 1824, p. 4.

29 “Aviso", en: Gaceta de Cartagena de Colombia, No. 171, noviembre 20 de 1824, p. 4.

30 Gaceta de Cartagena de Colombia, No. 175, diciembre 18 de 1824, p. 4.

${ }^{31}$ Ibídem.
} 
bre de 1825 que establecería en la plaza de mercado de la ciudad un café y billar, sitio en el cual los visitantes podían encontrar "decencia, equidad y toda comodidad". Prometió ofrecer una diversidad de licores y comestibles, así como periódicos y demás impresos que circulaban en la ciudad ${ }^{2}$. A finales de este año, Fermín Rosi anunció que, con ocasión de las fiestas nacionales, abriría su botillería y repostería cuidadosamente adornada y "completamente surtida y servida con el mayor esmero" donde los clientes podían hallar máxima comodidad 33 .

Siendo Cartagena el más importante puerto de Colombia en sus primeros años de vida republicana y, estando ya superadas las restricciones comerciales vividas en tiempos coloniales, fue continuo el flujo de comerciantes e inversionistas nacionales y extranjeros en busca de nuevas oportunidades. Cambiar de domicilio implicaba dejar resueltos todos los asuntos personales y económicos en esta ciudad y ese fue precisamente el motivo que impulsó a varios de estos comerciantes a publicar un aviso en la prensa en el que también aprovechaban la ocasión para poner en venta sus negocios.

Así por ejemplo, José Rastigue Bellegarde anunció a mediados de 1822 a través de la Gaceta que pronto saldría del país y, por ello, hacía un llamado para resolver cuentas pendientes y, de paso, ofreció su botillería ${ }^{34}$. Por su parte, Alfonso Cary informó por esos días que estaba dispuesto a dejar todos sus negocios arreglados y puso además en venta su almacén "haciendo grandes ventajas al comprador" 35.

En el mes de noviembre del año siguiente, Antonio Flucher expresó su deseo de arreglar sus cuentas y vender en 3.000 pesos su tienda localizada cerca de la capilla de los Dolores, su casa ubicada en la calle del Colegio y algunas mercancías disponibles como: aguardiente, vinos, vinagre de Castilla, jabón de Castilla y una esclava ${ }^{36}$. En abril de 1825, Luis Dejannon comunicó a través de la prensa su interés en saldar cuentas

\footnotetext{
32 "Aviso", en: Gaceta de Cartagena de Colombia, No. 213, septiembre 17 de 1825, p. 4.

33 "Otro", en: Gaceta de Cartagena de Colombia, No. 226, diciembre 17 de 1825, p. 4.

34 "Otro", en: Gaceta de Cartagena de Colombia, No. 17, junio 8 de 1822, p. 74.

35 "Aviso", en: Gaceta de Cartagena de Colombia, No. 19, junio 22 de 1822, p. 82.

36 “Aviso", en: Gaceta de Cartagena de Colombia, No. 118, noviembre 15 de 1823, p. 490.
} 
pendientes en el término de $\mathbf{2 4}$ horas pues debía partir prontamente hacia la ciudad de Londres37.

En el mes de agosto de este mismo año, Godfrey Phillips anunció a sus amigos y al público en general que se había mudado de su casa ubicada al frente de la catedral a una nueva sede en la esquina de la calle de los Dolores. Les recordó a los que tuviesen negocios pendientes con él para ponerlos a paz y salvo o de lo contrario "le será necesario dar algunos pasos que no les serán agradables" 38 .

\section{La reactivación del movimiento portuario}

Tan pronto Cartagena alcanzó su independencia definitiva en noviembre de 1821, una de las prioridades fue la reactivación del movimiento portuario que se había visto estancado por las restricciones impuestas por el antiguo régimen y la prolongada lucha emancipadora. Era deber de los buques nacionales y foráneos presentar documentos de registro de entrada y salida especificando si eran de carga o de pasajeros.

En prácticamente todas las ediciones de la Gaceta, la capitanía de puerto publicaba avisos que daban cuenta del movimiento de buques. A diferencia del monopolio imperante durante los tiempos del dominio hispánico, ahora en la naciente República era evidente el incremento de las rutas y de los contactos comerciales con otras naciones. Tal como lo revela el cuadro No. 1, la mayor cantidad de embarcaciones llegadas al puerto procedían de Jamaica, Riohacha, Portobelo, Chagres y Nueva York pero arribaban también de otras latitudes lejanas como Burdeos, Marsella y Estocolmo.

Cuadro No. 1: Entradas de embarcaciones al puerto de Cartagena registradas en la $\mathrm{Ga}$ ceta, $1822-1825$

\begin{tabular}{|l|c|l|}
\multicolumn{1}{c}{ Ciudad } & No. embarcaciones & \multicolumn{1}{c}{ Productos } \\
\hline Jamaica & 48 & $\begin{array}{l}\text { Cera, guanos, ron, caudales, cobre, mercancías, } \\
\text { caldos }\end{array}$ \\
\hline Riohacha & 29 & Palo de Brasil, palo de mora \\
\hline Portobelo & 25 & Vino, cacao, coco, cuero \\
\hline Chagres & 22 & Pasajeros, prisioneros, mercancías, coco, harina, \\
\hline
\end{tabular}

37 “Otro", en: Gaceta de Cartagena de Colombia, No. 192, abril 16 de 1825, p. 4.

38 “Aviso”, en: Gaceta de Cartagena de Colombia, No. 209, agosto 20 de 1825, p. 4. 


\begin{tabular}{|c|c|c|}
\hline & & vino, cacao, frutos del país \\
\hline Nueva York & 16 & $\begin{array}{l}\text { Mercancías, víveres, lonas, arroz, maíz, jarcias, } \\
\text { pintura, papeles oficiales para el cónsul, caldos }\end{array}$ \\
\hline Maracaibo & 11 & Caldos, tropas, anís, café \\
\hline Santa Marta & 11 & $\begin{array}{l}\text { Mercancías, pasajeros, harina, caldos, palo de Bra- } \\
\text { sil, carne, tropas }\end{array}$ \\
\hline Londres & 9 & Papeles oficiales, mercancías \\
\hline La Habana & 8 & Mercancías, café, azúcar, palo de Brasil \\
\hline Burdeos & 7 & Mercancías, caldos \\
\hline Liverpool & 5 & Mercancías \\
\hline Boston & 4 & $\begin{array}{l}\text { Mercancías, harina, bacalao, arenques, jabón ame- } \\
\text { ricano, vinagre, aguardiente, brines y silletas }\end{array}$ \\
\hline Baltimore & 4 & Harina, comestibles, víveres \\
\hline Santo Tomás & 4 & Mercancías, caldos \\
\hline Baltimore & 4 & Harina, comestibles, víveres \\
\hline Los Cayos & 4 & - \\
\hline Marsella & 4 & Caldos y mercancías \\
\hline Nicaragua & 3 & Palo de Brasil, mercancías \\
\hline New Orleans & 3 & Pasajeros, víveres, mercancías \\
\hline Guaira & 3 & - \\
\hline Providencia & 2 & - \\
\hline Curazao & 2 & - \\
\hline Isla de San Blas & 2 & Tortugas \\
\hline San Andrés & 2 & - \\
\hline Kingston & 1 & Mercancías \\
\hline Guárico & 1 & Harina \\
\hline Chocó & 1 & - \\
\hline Veracruz & 1 & Víveres \\
\hline Laguna de Perlas & 1 & - \\
\hline Puerto Cabello & 1 & - \\
\hline Charleston & 1 & Caldos, mercancías, papeles oficiales \\
\hline Sisal & 1 & Cueros y tabacos \\
\hline $\begin{array}{l}\text { Islas Bass (Estados } \\
\text { Unidos) }\end{array}$ & 1 & Madera, efectos navales \\
\hline Hamburgo & 1 & Mercancías \\
\hline Costa de Florida & 1 & Harina \\
\hline Sabanilla & 1 & Palo de Brasil \\
\hline Bahía Honda & 1 & - \\
\hline $\begin{array}{l}\text { Cabo de San Anto- } \\
\text { nio }\end{array}$ & 1 & - \\
\hline
\end{tabular}




\begin{tabular}{|l|l|l|}
\hline Estocolmo & 1 & Hierro y otras mercancías \\
\hline Filadelfia & 1 & Provisiones \\
\hline Gibraltar & 1 & Vino, papel \\
\hline
\end{tabular}

Fuente: Gaceta de Cartagena de Colombia, No. 4-216.

Jamaica, Riohacha y Portobelo figuraban también como los principales puertos de destino de las embarcaciones que partían de Cartagena llevando frutos del país y otra serie de productos. Otras naves viajaban hacia Europa y Estados Unidos.

\section{Cuadro No. 2}

Salida de embarcaciones del puerto de Cartagena registradas en la Gaceta, 1822-1825

\section{Ciudad}

\section{Jamaica}

Riohacha

Portobelo

Chagres

Nueva York

Londres

Los Cayos

Sabanilla

Baltimore

Cuba

Santo Tomás

Charleston

Maracaibo

Providencia

Boston

Curazao

San Andrés

Liverpool

Costa del Darién

Portland

Isla de San Blas

Chocó

\section{No. embarcaciones}

\section{7}

27

18

9

8

7

7

7

5

4

4

3

3

3

3

3

3

3

2

2

2

2

1

1

1

\section{Productos}

frutos del país, palo de mora, harina, añil, algodón, pasajeros

Maíz, harina, esteras, palo de Brasil, aguardiente, papeles oficiales, vino, ron, frutos del país

Papeles de gobierno, tropas, frutos del país

Aceite, higos, almendras, avellanas, vino, mercancías

Bálsamo, añil, cacao, cobre, carey, coco, tropas

Frutos del país

Frutos del país, cueros, canela, añil, palo de Brasil y palo de mora

Frutos del país

Frutos del país, cueros, palo de mora

Prisioneros

Frutos del país, cocos

Frutos del país

Frutos del país

Comestibles, trigo

Cueros, palo de mora, frutos del país

Cueros, palo de mora

-

Mercancías

Frutos del país 


\begin{tabular}{|l|l|l|}
\hline Coro & 1 & Frutos del país \\
\hline New Orleans & 1 & Cobre viejo \\
\hline Trujillo & 1 & Frutos del país \\
\hline Martinica & 1 & - \\
\hline Puerto Cabello & 1 & - \\
\hline Lorica & 1 & - \\
\hline Havre de Grace & 1 & Frutos del país \\
\hline Tampico & 1 & - \\
\hline Campeche & 1 & - \\
\hline Cumaná & 1 & - \\
\hline Marsella & 1 & Frutos del país \\
\hline Burdeos & 1 & Frutos del país \\
\hline
\end{tabular}

Fuente: Gaceta de Cartagena de Colombia, No. 4-216.

Además de esta serie de registros oficiales, regularmente solían aparecer avisos especiales en los que algunos particulares dueños de buques anunciaban viajes hacia diferentes destinos, ofreciéndose posibilidades de transporte para personas y mercancías. A continuación se transcribe un aviso de este tipo:

La muy velera fragata colombiana Rita, forrada en cobre, su capitán Bautista Lies, dará la vela para Liverpool en todo el mes de noviembre entrante, admite flete y pasajeros, tiene superior comodidad. Se despacha en casa del Señor Lázaro María de Herrera. Cartagena, octubre 29 de $1824^{39}$.

Veamos este otro aviso que anunciaba por esos días la partida de una embarcación con destino nacional: "Para el 31 estará listo el campano Santa Teresa para seguir al Chocó, admite carga y pasajeros" 40 .

Por esta época fue muy común enviar papeles oficiales por vía marítima, principalmente hacia las ciudades costeras de Riohacha y Santa Marta. Por otro lado, vale decir que el flujo de embarcaciones reflejaba el ambiente de tensión militar que se vivía en las aguas del mar Caribe a causa de los últimos coletazos de las fuerzas españolas. En mayo de 1823 arribó la goleta de guerra Luisa, capitaneada por José Eduardo Casas,

\footnotetext{
39 “Aviso", en: Gaceta de Cartagena de Colombia, No. 168, octubre 30 de 1824, p. 4.

40 “Aviso”, en: Gaceta de Cartagena de Colombia, No. 145, mayo 22 de 1824, p. 608.
} 
apresada en el lago de Maracaibo a finales del mes anterior por la goleta Atrevida. La nave incautada se hallaba cargada con palo de Brasil, 18 esclavos y 27 soldados heridos que quedaron a disposición de las autoridades republicanas ${ }^{41}$.

Por estos años todavía se veía movimiento de tropa por vía marítima, como fue el caso de las huestes que en el mes de marzo de 1824 salieron en seis barcos hacia Portobelo o de las cuatro naves que ingresaron con tropas procedentes de Maracaibo. Otra de las consecuencias del conflicto político y militar contra los últimos reductos españoles fue el traslado de reos. Un ejemplo de ello fueron los prisioneros que a mediados de este mismo año salieron desterrados a Cuba en la goleta nacional Indiana.

En los avisos de prensa también quedó constancia de los trámites para la mejora en el servicio y los controles ejercidos por las autoridades portuarias. Según disposición gubernamental, se dio autorización en diciembre de 1825 para construir unas bodegas en la isla de Manga con el fin de depositar allí cueros, palo de mora, algodones y otros productos, con lo cual se ahorrarían gastos en el proceso de descarga, conducción al muelle y traslado al almacén. Félix Martín de León, propietario de la isla, ofreció entablar negociaciones con el fin de llegar a un ajuste en el precio del arrendamiento del terreno ${ }^{4}$. El guardamayor de las rentas nacionales de la plaza de Cartagena, Tomás Madiedo, certificó el 25 de abril de 1824 que, en la inspección que hizo a la fragata de guerra $\mathrm{Ve}$ nezuela, no detectó elementos que fuesen objeto de derechos de renta43.

En los almacenes de la aduana se reportaron a finales de este año varias encomiendas que aún no habían sido reclamadas por sus destinatarios. Así entonces, fue publicado un aviso en el que se describían estos elementos: siete cajas y un baúl forrados en tejido de fique procedentes de Jamaica en la goleta inglesa Lady Rowley que había entrado a Cartagena el 18 de noviembre. Por otro lado, se reportaron seis bocoyes y dos barriles provenientes de Liverpool en el bergantín inglés Elisa que había tocado puerto el 16 de diciembre de este mismo año. A los interesados se les fijó un plazo perentorio de

\footnotetext{
41 "Noticias comerciales", en: Gaceta de Cartagena de Colombia, No. 80, mayo 17 de 1823, p. 338. 42 "Aviso", en: Gaceta de Cartagena de Colombia, No. 225, diciembre 10 de 1825, p. 4. 43 “Aviso", en: Gaceta de Cartagena de Colombia, No. 142, mayo $1^{\circ}$ de 1824, p. 594.
} 
tres meses para reclamar esta mercancía o de lo contrario quedaría a disposición del gobierno44.

\section{Ventas de bienes y productos}

Del total de avisos publicados en la Gaceta, la mayor parte correspondía a la venta de bienes y productos de diversa índole, lo cual reflejaba de alguna manera el activo comercio que se vivía en la ciudad de Cartagena.

Tal como se observa en el cuadro insertado a continuación, entre los bienes de finca raíz, los más ofrecidos a través de las páginas del periódico fueron las casas y le seguían en su orden las haciendas y en menor proporción los solares.

Cuadro No. 3

Bienes comercializados a través de la Gaceta

Bienes comercializados

\section{Casas}

Haciendas

Solares

Islas

Tiendas o almacenes

\begin{tabular}{|c|}
\hline No \\
\hline 31 \\
8 \\
\hline 2 \\
1 \\
\hline
\end{tabular}

Embarcaciones

Esclavos

No.

31

8

2

1

3

5

Fuente: Gaceta de Cartagena de Colombia, No. 2-226.

44 “Aviso”, en: Gaceta de Cartagena de Colombia, No. 183, febrero 12 de 1825, p. 4. 
En total, se inventariaron 13 casas altas de dos plantas muy comunes en el centro de la ciudad45, las cuales alcanzaron los más altos precios, como la casa No. 5 de la calle Ventana del Hierro en el barrio Santa Catalina avaluada en 4.080 pesos o aquella otra ubicada en la calle de las Carretas que incluía dos tiendas con puerta exterior, un almacén y un aljibe. Adicionalmente aparecían registradas 18 casas bajas, las cuales por lo general se negociaban a un menor precio. Algunas viviendas estaban comprometidas con gravamen, como por ejemplo la casa con solar de propiedad de Josef Santiago Martínez y Mendinueta, ubicada en la calle de la cochera de Lobo, avaluada en 4.310 pesos y gravada en 2.006 pesos.

Las haciendas de la provincia de Cartagena fueron importantes escenarios de las guerras de Independencia como fuente de provisión de tropas y como base de operaciones. Estos centros de producción tardarían muchos años en recuperarse de la crisis económica en que estaban sumidas tras los efectos devastadores de este conflicto militar por cuenta del saqueo, el embargo y las ocupaciones de hecho46. El estado de decadencia de estas propiedades rurales se vio reflejado en las ofertas de venta publicadas en la Gaceta, tal como lo indica el siguiente cuadro:

Cuadro No. 4

Avisos de venta de haciendas de la provincia de Cartagena publicados en la Gaceta,

1822-1825

\begin{tabular}{|c|c|c|c|c|}
\hline Hacienda & Ubicación & Tamaño y producción & $\begin{array}{c}\text { Valor } \\
\text { comercial } \\
\text { en pesos }\end{array}$ & Año \\
\hline $\begin{array}{l}\text { San Antonio de } \\
\text { Guayabal }\end{array}$ & $\begin{array}{l}\text { En jurisdicción de } \\
\text { Santa Rosa }\end{array}$ & - & 10.425 & 1822 \\
\hline $\begin{array}{l}\text { San José de } \\
\text { Chiricoco }\end{array}$ & $\begin{array}{l}\text { En jurisdicción de } \\
\text { Santa Rosa }\end{array}$ & e & 4.228 & 1823 \\
\hline $\begin{array}{l}\text { Santa Rita de la } \\
\text { Perdiz de pro- } \\
\text { piedad del } \\
\text { presbítero Lo- } \\
\text { renzo José Pi- }\end{array}$ & $\begin{array}{l}\text { A legua y media de } \\
\text { la villa de Tolú }\end{array}$ & $\begin{array}{l}4 \text { esclavos, bestias mulares y caballa- } \\
\text { res, } 5 \text { tablas de caña, casas de vivienda } \\
\text { y de trapiches con todos los utensilios } \\
\text { necesarios para su beneficio, un fondo } \\
\text { de cobre, } 800 \text { árboles de coco "parin- }\end{array}$ & 5.000 & 1823 \\
\hline
\end{tabular}

45 Monika Therrien, "El espacio urbano de Cartagena en la Colonia”, en: Historia Crítica, No. 2, Bogotá, Universidad de Los Andes, julio-diciembre de 1989, p. 115.

46 Hermes Tovar Pinzón, "La lenta ruptura con el pasado colonial”, en Historia económica de Colombia, Bogotá, Tercer Mundo Editores, $4^{\mathrm{a}}$ edición, 1994, pp. 92-94; Roger Pita Pico, "El impacto de las guerras de Independencia en las haciendas esclavistas de la provincia de Cartagena", en Huellas Vol. 98, Barranquilla, Revista de la Universidad del Norte, julio-diciembre de 2015, pp. 4, 10. 


\begin{tabular}{|c|c|c|c|c|}
\hline $\begin{array}{l}\text { nedo, cura de la } \\
\text { parroquia de } \\
\text { Morroa }\end{array}$ & & $\begin{array}{l}\text { deros" y } 200 \text { más "pollones" a orilla } \\
\text { del mar }\end{array}$ & & \\
\hline $\begin{array}{l}\text { Santa Rita de } \\
\text { Flecha de pro- } \\
\text { piedad de Juan } \\
\text { Eusebio Gue- } \\
\text { rrero }\end{array}$ & $\begin{array}{l}\text { En el camino entre } \\
\text { Zipacoa y San Es- } \\
\text { tanislao }\end{array}$ & $\begin{array}{l}6 \text { tablas de caña, } 4 \text { burros, } 4 \text { caballos } \\
\text { de tirar, } 6 \text { tablas de platanal, } 1 \text { casa } \\
\text { con su trapiche, } 3 \text { fondos, } 1 \text { casa de } \\
\text { habitación con su cocina y hornillas, } \\
\text { mesas y moldes de hacer panela, } 3 \\
\text { cajones para depósito de mieles }\end{array}$ & - & 1823 \\
\hline $\begin{array}{l}\text { “Juan Domín- } \\
\text { guez", alias San } \\
\text { Gregorio de } \\
\text { Caracolí de } \\
\text { propiedad de } \\
\text { José Antonio } \\
\text { Ripoll }\end{array}$ & $\begin{array}{l}\text { A } 11 \text { leguas de dis- } \\
\text { tancia de Cartage- } \\
\text { na, en el sitio de } \\
\text { Santa Catalina }\end{array}$ & $\begin{array}{l}\text { Una extensión de } 21 \text { caballerías, con } \\
\text { cría de ganados y cultivos }\end{array}$ & - & 1823 \\
\hline Santa Cruz & $\begin{array}{l}\text { Camino entre } \mathrm{Zi}- \\
\text { pote y Lorica }\end{array}$ & $\begin{array}{l}6 \text { caballerías de extensión, tierras férti- } \\
\text { les para siembras y árboles frutales }\end{array}$ & - & 1824 \\
\hline Una hacienda & $\begin{array}{l}\text { En los sitios de } \\
\text { Santa Catalina, } \\
\text { Villanueva y Arro- } \\
\text { yogrande }\end{array}$ & $\begin{array}{l}\text { Con abundancia de agua y tierras ap- } \\
\text { tas para la cría de ganados y el cultivo } \\
\text { de árboles de cacao, mameyes y agua- } \\
\text { cates }\end{array}$ & - & 1825 \\
\hline Honduras & $\begin{array}{l}\text { En jurisdicción de } \\
\text { Tolú a dos leguas } \\
\text { de María La Baja }\end{array}$ & $\begin{array}{l}18 \text { caballerías de tierra con abundantes } \\
\text { bosques y maderas, } 4 \text { esclavos, } 4 \text { cua- } \\
\text { dros de caña, casa y trapiche con mo- } \\
\text { lino y horno, casa de vivienda entabla- } \\
\text { da }\end{array}$ & $\begin{array}{l}8.079, \text { gra- } \\
\text { vada en } \\
3.824\end{array}$ & 1825 \\
\hline
\end{tabular}

Fuente: Gaceta de Cartagena de Colombia, No. 111-225.

Dentro de los avisos de bienes raíces, figura uno muy curioso que correspondía a la venta de la isla San Francisco de Maparapa en inmediaciones de la bahía de Cartagena, cerca a Cospique. Constaba de dos caballerías de tierra y tenía varios árboles frutales y de 500 a 600 palmas de coco. Los interesados en adquirir este predio debían contactarse con María de Jesús Amador47. Otro singular anuncio fue el que apareció publicado a principios de 1823 cuando se ofreció una huerta de verduras en la calle de los Siete Infantes en la casa perteneciente al maestro Juan Rafael de Cuestas ${ }^{48}$.

47 “Aviso", en: Gaceta de Cartagena de Colombia, No. 22, julio 13 de 1822, p. 98.

48 “Aviso", en: Gaceta de Cartagena de Colombia, No. 46, diciembre 28 de 1822, p. 194. 
Tres tiendas fueron ofrecidas, una de ellas de propiedad de Francisco Hipólito Lecor en la calle de Lozano49. Otras más, como vimos en uno de los anteriores acápites, fueron vendidas por cambio de domicilio de sus dueños.

Entre los bienes muebles transados con mayor valor figuraban los esclavos, las embarcaciones y algunos animales como fue el caso de dos caballos de buen paso y dos potros ofrecidos en venta.

Desde las décadas finales del siglo XVIII, la esclavitud negra en la costa Caribe había entrado en franca decadencia debido a factores como la crisis económica, el creciente mestizaje, el cimarronismo y las oportunidades de manumisión ${ }^{5}$. Con relación a su valor, es importante tener presente que los esclavos llegaron a representar un capital apreciable dentro del cúmulo de pertenencias alcanzando incluso a tener mayor peso dentro del total del patrimonio.

La tendencia general en los años turbulentos del periodo de Independencia y de la naciente República en materia de mercado esclavista fue la disminución del número de transacciones y la contracción en los precios. Lo único cierto es que esta comercialización nunca se detuvo pese a los embates propios de la lucha política y militar.

La promoción de este tipo de transacciones se hizo aún más visible con el auge experimentado por la prensa durante esta época, en donde solían aparecer anuncios de venta con detalles físicos, habilidades laborales, formas de comportamiento y el precio asignado a cada "pieza". Tamaña paradoja la de algunos de estos medios escritos que, por una parte, sentaban una férrea defensa abolicionista ${ }^{51}$, y por otra, promocionaban al detal el "mercado humano".

Tal como se observa en el cuadro insertado a continuación, la mayoría de esclavos eran jóvenes en plena edad productiva y en buena parte correspondían a mujeres requeridas para labores domésticas.

49 “Aviso”, en: Gaceta de Cartagena de Colombia, No. 99, julio 23 de 1823, p. 414.

50 Jaime Jaramillo Uribe, Ensayos de Historia Social, Bogotá, Tercer Mundo-Uniandes, 1987, p. 76.

${ }^{51}$ Roger Pita Pico, "La manumisión en la costa Caribe colombiana durante el proceso de Independencia: vicisitudes de una ilusión aplazada, 1810-1825", en Historia Caribe, Vol. VIII, No. 22, Barranquilla, Universidad del Atlántico, enero-junio de 2013, pp. 43-73. 
Cuadro No. 5

Esclavos comercializados a través de las páginas de la Gaceta, 1822-1825

\begin{tabular}{|c|c|c|c|c|}
\hline Transacción & Esclavo & $\begin{array}{l}\text { Características fenotípicas y destre- } \\
\text { zas }\end{array}$ & Precio & Año \\
\hline Venta & Negra & 30 años de edad & - & 1822 \\
\hline Venta & Negra & $\begin{array}{l}\text { Joven de } 25 \text { años de edad, planchadora, } \\
\text { sana y sin tachas }\end{array}$ & 250 pesos & 1823 \\
\hline Venta & Negro & $\begin{array}{l}28 \text { años de edad, buena estatura, sano y sin } \\
\text { tachas }\end{array}$ & 250 pesos & 1823 \\
\hline Venta & $\begin{array}{l}\text { Negra de propiedad } \\
\text { de Antonio Flucher }\end{array}$ & $\begin{array}{l}18 \text { años de edad, sana y sin tachas, "fabrica } \\
\text { cigarros, lava bien y entiende algo de coci- } \\
\text { na" }\end{array}$ & 180 pesos & 1823 \\
\hline Venta & Zamba & $\begin{array}{l}18 \text { años de edad, sabe hacer tabacos, moler } \\
\text { chocolate y otras labores de servicio do- } \\
\text { méstico }\end{array}$ & $\begin{array}{l}200 \text { pe- } \\
\text { sos }\end{array}$ & 1823 \\
\hline Venta & $\begin{array}{l}\text { Mulata de color } \\
\text { claro, llamada María } \\
\text { del Pilar Mármol, } \\
\text { esclava de Santiago } \\
\text { Capuro }\end{array}$ & $\begin{array}{l}18 \text { años de edad, sabe cocinar "con perfec- } \\
\text { ción" y lava "regular" }\end{array}$ & - & 1823 \\
\hline Venta & Negro Felipe & 58 años de edad de oficio zapatero & 50 pesos & 1823 \\
\hline Compra & Negra & $\begin{array}{l}\text { Parida y sin cría y de salud robusta para } \\
\text { servir en la casa }\end{array}$ & - & 1823 \\
\hline Venta & $\begin{array}{l}\text { Negra Ventura Mi- } \\
\text { randa }\end{array}$ & 23 años de edad, sabe lavar y cocinar & $\begin{array}{l}200 \text { pe- } \\
\text { sos }\end{array}$ & 1824 \\
\hline Venta & $\begin{array}{l}\text { Negra de propiedad } \\
\text { de Antonio Flucher }\end{array}$ & 14 años de edad, sana y sin tachas & $\begin{array}{l}180 \text { pesos } \\
\text { o trueque } \\
\text { por ropa }\end{array}$ & 1824 \\
\hline Venta & $\begin{array}{l}\text { Morena Juana Ruíz } \\
\text { de propiedad de la } \\
\text { viuda Victoria He- } \\
\text { rrera }\end{array}$ & $\begin{array}{l}27 \text { años de edad, con hija de } 3 \text { años, buena } \\
\text { lavandera y cocinera, sana y sin tachas }\end{array}$ & $\begin{array}{l}300 \text { pe- } \\
\text { sos }\end{array}$ & 1824 \\
\hline Venta & Esclava & 20 años de edad, ágil y robusta & $\begin{array}{l}200 \text { pe- } \\
\text { sos }\end{array}$ & 1824 \\
\hline Venta & Esclavo & - & 150 pesos & 1824 \\
\hline Venta & $\begin{array}{l}\text { Negro criollo Benito } \\
\text { Robles }\end{array}$ & $\begin{array}{l}24 \text { años de edad, robusto y de buena pre- } \\
\text { sencia }\end{array}$ & & 1824 \\
\hline Venta & Esclava & $\begin{array}{l}23 \text { años de edad, robusta, "buena lavandera } \\
\text { y cocinera" }\end{array}$ & $\begin{array}{l}200 \text { pe- } \\
\text { sos }\end{array}$ & 1824 \\
\hline Venta & Esclava & $\begin{array}{l}17 \text { años, con principios básicos en la cocina } \\
\text { y en lavar }\end{array}$ & 180 pesos & 1824 \\
\hline
\end{tabular}

Fuente: Gaceta de Cartagena de Colombia, No. 79-209. 
En los tres años objetos de este estudio aparecieron cuatro avisos de embarcaciones en venta. Algunas de estas naves eran de mayor envergadura como la balandra La Unión del Porte de 15 toneladas o la balandra dinamarquesa nombrada Carmen de 23 toneladas, procedente de Cuba y "lista para navegar", pregonada en diciembre de 1823 en la casa de Lázaro María de Herrera. Asimismo, se ofrecieron otro tipo de navíos más modestos como la canoa Santa Teresa, vendida a finales de 1823 en 1.400 pesos $^{52}$.

Aunque con un valor mucho menor, vale mencionar también otro tipo de productos ofrecidos a través de los avisos de prensa, como es el caso de los libros, las revistas y los folletos (ver Cuadro No. 6). Estos datos resultan interesantes para examinar qué tipo de obras circulaban en la ciudad, algunas de ellas procedentes de Europa53. De igual manera, con esta información es posible observar además las tendencias culturales en esta etapa de transición entre el antiguo régimen y las ideas liberales propias del sistema republicano.

De un total de 27 obras promocionadas, 4 eran de carácter religioso, 3 sobre cultura universal, 2 sobre literatura y 1 sobre medicina. Aparecen también 10 libros y cartillas educativas dirigidas a los estudiantes de las escuelas y colegios, lo cual se enmarcaba en el proyecto educativo impulsado durante estos años por el vicepresidente Santander. Asimismo, se ofrecieron en venta 3 obras sobre temas patrióticos y 4 títulos sobre política y Estado. Las publicaciones podían adquirirse en las imprentas y tiendas de la ciudad.

Cuadro No. 6

Lista de libros ofrecidos en los avisos de la Gaceta, 1822-1825

\begin{tabular}{|l|l|l|}
\hline \multicolumn{1}{|c|}{ Obra } & Precio & \multicolumn{1}{c|}{ Lugar de expendio } \\
\hline $\begin{array}{l}\text { La respuesta del León de Venecia al gallo de San } \\
\text { Pedro }\end{array}$ & 4 reales & Imprenta de la Gaceta \\
\hline $\begin{array}{l}\text { Compendio de la gramática y ortografía castellana } \\
\text { para el uso de los niños de escuelas de primeras } \\
\text { letras }\end{array}$ & - & $\begin{array}{l}\text { Tienda de Félix Barco en la } \\
\text { calle del Colegio }\end{array}$ \\
\hline
\end{tabular}

52 "Aviso", en: Gaceta de Cartagena de Colombia, No. 123, diciembre 20 de 1823, p. 514; "Aviso", en: Gaceta de Cartagena de Colombia, No. 120, noviembre 29 de 1823, p. 502.

53 De ese tenor fue un anuncio fechado a mediados de 1825, en el que se informaba la llegada de libros publicados en la ciudad de París sobre diversos temas de interés, obras que podían adquirirse en la casa de la antigua Inquisición. "Aviso", en: Gaceta de Cartagena de Colombia, No. 226, diciembre 17 de 1825 , p. 4 . 


\begin{tabular}{|c|c|c|}
\hline Calendario Impreso 1824 & 4 reales & $\begin{array}{l}\text { Imprenta calle de Badillo y } \\
\text { tienda de Mariano Aparicio } \\
\text { en la plaza de las Yerbas }\end{array}$ \\
\hline Cuerpo de Leyes de la República (tomo I) & 20 reales & Administración de Correos \\
\hline Lecciones de Lógica para el curso de Filosofía & - & Imprenta de la Gaceta \\
\hline Guillermo Tell o la Suiza libre & 6 reales & $\begin{array}{l}\text { Imprenta de la Gaceta y } \\
\text { tienda del ciudadano Ma- } \\
\text { nuel Dorado }\end{array}$ \\
\hline Calendario impreso 1823 & - & Imprenta de la Gaceta \\
\hline $\begin{array}{l}\text { Disertación sobre los principios del Gobierno por } \\
\text { Tomás Pain }\end{array}$ & 5 reales & $\begin{array}{l}\text { Imprenta de la Gaceta y } \\
\text { esquina de los Dolores }\end{array}$ \\
\hline $\begin{array}{l}\text { Elogio al Excelentísimo Señor Libertador Simón } \\
\text { Bolívar }\end{array}$ & 1 real & $\begin{array}{l}\text { Fonda de Madame Juliana } \\
\text { López }\end{array}$ \\
\hline Poema. Pérfido carácter de don Tomás Morales & - & $\begin{array}{l}\text { Fonda de Madame Juliana } \\
\text { López }\end{array}$ \\
\hline Catecismo de Agricultura & - & $\begin{array}{l}\text { Imprenta de la Gaceta y } \\
\text { almacén de Juan B. Calcaño } \\
\text { en la plaza de la Aduana }\end{array}$ \\
\hline Catecismo de Moral & - & $\begin{array}{l}\text { Imprenta de la Gaceta y } \\
\text { almacén de Juan B. Calcaño } \\
\text { en la plaza de la Aduana }\end{array}$ \\
\hline Catecismo de industria rural y doméstica & - & $\begin{array}{l}\text { Imprenta de la Gaceta y } \\
\text { almacén de Juan B. Calcaño } \\
\text { en la plaza de la Aduana }\end{array}$ \\
\hline Variedades o Mensajero de Londres, No. V y VI & - & $\begin{array}{l}\text { Imprenta de la Gaceta y } \\
\text { almacén de Juan B. Calcaño } \\
\text { en la plaza de la Aduana }\end{array}$ \\
\hline Museo Universal de Ciencias y de Artes, No. II y III & - & $\begin{array}{l}\text { Imprenta de la Gaceta y } \\
\text { almacén de Juan B. Calcaño } \\
\text { en la plaza de la Aduana }\end{array}$ \\
\hline El Nuevo Testamento & - & $\begin{array}{l}\text { Imprenta de la Gaceta y } \\
\text { almacén de Juan B. Calcaño } \\
\text { en la plaza de la Aduana }\end{array}$ \\
\hline Educación Gimnástica del bello sexo & - & $\begin{array}{l}\text { Imprenta de la Gaceta y } \\
\text { almacén de Juan B. Calcaño } \\
\text { en la plaza de la Aduana }\end{array}$ \\
\hline Derechos del hombre y del ciudadano & - & Imprenta de la Gaceta \\
\hline $\begin{array}{l}\text { Memorias sobre el influjo de los climas cálidos. } \\
\text { Ensayo analítico sobre la naturaleza, causas y cu- } \\
\text { ración de las calenturas termodinámica y termo } \\
\text { atáxica, llamadas calentura amarilla de Ámérica, } \\
\text { vómito prieto por José Fernández de Madrid }\end{array}$ & 12 reales & Imprenta de la Gaceta \\
\hline La Biblioteca Americana (obra seriada) & 6 pesos & $\begin{array}{l}\text { Antigua sede del estanco de } \\
\text { aguardiente }\end{array}$ \\
\hline $\begin{array}{l}\text { Catecismo Político arreglado a la Constitución de } \\
\text { la República de Colombia (nueva edición) }\end{array}$ & - & Imprenta de la Gaceta \\
\hline Poesías de José Fernández de Madrid & - & Imprenta de la Gaceta \\
\hline
\end{tabular}




\begin{tabular}{|c|c|c|}
\hline $\begin{array}{l}\text { La América Libertada por el invicto Bolívar, tragi- } \\
\text { comedia en tres actos }\end{array}$ & - & Imprenta de la Gaceta \\
\hline $\begin{array}{l}\text { Compendio de la Gramática castellana, dispuesta } \\
\text { en diálogo para el uso de las escuelas de primeras } \\
\text { letras }\end{array}$ & - & Imprenta de la Gaceta \\
\hline Espíritu de la Biblia y moral universal & - & Imprenta de la Gaceta \\
\hline El Evangelio en triunfo & - & Imprenta de la Gaceta \\
\hline Cartillas & - & Imprenta de la Gaceta \\
\hline Tablas para aprender a contar & - & Imprenta de la Gaceta \\
\hline Conocimientos en castellano y en inglés & - & Imprenta de la Gaceta \\
\hline
\end{tabular}

Fuente: Gaceta de Cartagena de Colombia, No. 23-226.

En ocasiones, se ofrecía la suscripción a algunas obras seriadas, como por ejemplo la revista editada en Londres por la Sociedad de Americanos, titulada La Biblioteca Americana54. Se promocionó igualmente la obra titulada Memorias sobre el influjo de los climas cálidos, la cual tenía como objeto analizar el origen, método curativo y prevención de enfermedades como el cólera, la disentería y la fiebre amarilla. Esta obra había sido premiada por la Sociedad Patriótica de La Habana con 200 pesos y patente de socio de mérito. Fue publicada por primera vez en 1824 pero se había agotado rápidamente. Los interesados en adquirirla debían dejar en la imprenta su nombre y dirección55.

Otro de los productos que tuvo un buen cubrimiento en la sección de avisos fue el del juego de lotería. Varios anuncios daban cuenta de la venta de boletas y publicación de resultados tanto de la lotería municipal de Mompós como de la lotería municipal de Cartagena.

Para el caso de la lotería de Cartagena, en septiembre de 1822 se anunció que en uno de los entresuelos de la antigua casa de la Inquisición se ofrecerían billetes de este juego de azar. A través del reglamento interno, la Intendencia prometió todas las garantías necesarias pues se reconfirmó la disponibilidad de los fondos para distribuir entre los ganadores. Para mayor seguridad, se nombró como claveros al alcalde, al administrador y al regidor 56 .

\footnotetext{
54 “Aviso", en: Gaceta de Cartagena de Colombia, No. 133, febrero 28 de 1824, p. 554.

55 “Aviso", en: Gaceta de Cartagena de Colombia, No. 185, febrero 26 de 1825, p. 4.

56 “Aviso", en: Gaceta de Cartagena de Colombia, No. 32, septiembre 21 de 1822, p. 138.
} 
Sin embargo, no dejaron de presentarse obstáculos en la realización de este juego de azar. Así por ejemplo, a través de la prensa se informó el 4 de noviembre que el sorteo realizado cinco días atrás no podía verificarse por no tenerse razón de los billetes vendidos en los cantones de Santa Marta, Plato, Valledupar, Barranquilla y Corozal. Por lo tanto, se estaba a la espera de programar un nuevo sorteo, lo cual implicaba devolver el dinero a quienes ya habían realizado sus apuestas57. Otro de los impasses fue el ambiente de guerra que a principios de mayo de 1823 provocó la suspensión del sorteo ${ }^{58}$. En otras veces, el juego padecía retrasos por no poder salir a tiempo los billetes por cuenta de las múltiples ocupaciones de la imprenta59.

A mediados de 1825 se decidió elevar el monto de los premios tras haberse experimentado una "buena acogida" no solo por parte de los cartageneros sino también de otros pueblos de la provincia. Igualmente se subrayó el hecho de que había mejorado la suerte de varios ciudadanos, quienes habían salido de su estado de pobreza. Las utilidades de este juego eran destinadas para el aseo de la ciudad y se tenía proyectado hacer una obra de servicio al público ${ }^{60}$.

En los avisos de venta había cabida también para ofrecer algunas innovaciones. A comienzos del año siguiente se promocionó un avance de la medicina: las ligaduras umbilicales y bragueros elásticos del Dr. Hull, su inventor. Esto se anunció como una cura segura para la hernia pues el invento ya había merecido la patente perpetua del gobierno de Estados Unidos ${ }^{61}$.

\section{Ofrecimiento de servicios particulares}

Una ciudad como Cartagena, en su condición de puerto de ultramar, mantenía una intensa actividad económica. No es fortuito entonces que allí prosperara una variada

57 Gaceta de Cartagena de Colombia, No. 39, noviembre 9 de 1822, p. 166.

58 “Aviso", en: Gaceta de Cartagena de Colombia, No. 77, mayo $1^{\circ}$ de 1823, p. 326.

59 Gaceta de Cartagena de Colombia, No. 181, enero 29 de 1825, p. 4.

60 "Aviso", en: Gaceta de Cartagena de Colombia, No. 204, julio 9 de 1825, p. 4.

61 “Aviso", en: Gaceta de Cartagena de Colombia, No. 136, marzo 20 de 1824, p. 570. 
gama de oficios y servicios que en ocasiones utilizaban a la prensa como canal de difusión.

La lista de avisos podía incluir desde servicios de empleadas para labores domésticas hasta profesionales especializados. Con el fin de ampliar el poder de persuasión, los anunciantes recurrían a frases sugestivas para imprimirle mayor realce a sus servicios. En agosto de 1822 se hizo un llamado a quien estuviera interesado en administrar un café instalado en la casa No. 12 de la calle de las Carretas ${ }^{62}$. En el mes de abril de 1824 un ciudadano publicó un aviso en el que requería los servicios de una mujer libre ${ }^{63}$ para las labores domésticas ${ }^{64}$. A finales del año siguiente se solicitaron los servicios de una criada que supiera lavar y cocinar bien 65 .

Aunque muy esporádicos, también se dio el caso de algunos avisos en los que algún ciudadano se ofrecía a trabajar en un oficio en particular para el cual contaba con experiencia ganada. Esa fue la intención de un joven de 17 años que en octubre de 1825 manifestó su voluntad de trabajar en una tienda o bodega, para lo cual aseguró saber escribir y contar66.

Aquellas personas diestras en oficios especializados recurrían también a los avisos de prensa con la esperanza de ver incrementada su clientela. La señora Michell, residente en la calle de San Agustín, anunció al público que "[...] tiñe y compone sombreros y también quita toda especie de manchas a la ropa de paño"67. Prometió despachar con "celeridad" y a precios modestos. Guillermo Lamothe, maestro talabartero y guarniciero68 de berlinas, ofreció sus servicios de elaboración de carruajes y sillas de montar para señoras, en su local de la casa No. 19 de la calle de San Agustín69.

62 "Otro", en: Gaceta de Cartagena de Colombia, No. 25, agosto 3 de 1822, p. 110.

${ }^{63}$ La denominación "libre" se utilizaba para marcar la diferencia con las criadas esclavas.

64 “Aviso", en: Gaceta de Cartagena de Colombia, No. 140, abril 17 de 1824, p. 586.

65 “Aviso", en: Gaceta de Cartagena de Colombia, No. 218, octubre 22 de 1825, p. 4.

66 "Otro", en: Gaceta de Cartagena de Colombia, No. 216, octubre 8 de 1825, p. 4.

67 “Aviso”, en: Gaceta de Cartagena de Colombia, No. 164, octubre 2 de 1824, p. 4.

${ }^{68}$ Es el que se encarga de dar forma al cuero con sus manos para la creación de sillas de montar, polainas y guarniciones.

${ }^{69}$ Gaceta de Cartagena de Colombia, No. 177, enero $1^{\circ}$ de 1825 , p. 4. 
C. I. Maddix arribó a principios de diciembre de 1825 a Cartagena procedente de Jamaica acompañado de un grupo de artesanos con el fin de ofrecer en la ciudad sus servicios en: carpintería, albañilería, elaboración de coches, marca de monumentos, fabricación de escudos de armas "con el mayor gusto y pulidez" y producción de buques y botes. Prometió trabajar "[...] con estricta atención y puntualidad en la pronta ejecución y despacho de obras que le confíen a su cargo"70. En la siguiente edición del periódico, Juan Antonio Calvo anunció al público que había instalado su imprenta en la calle de San Agustín, para lo cual prometió prontitud y eficiencia en los trabajos que le fueran encomendados ${ }^{71}$.

En los anuncios se ofrecieron también profesionales, particularmente en el área del Derecho y la medicina. Mediante aviso divulgado a finales de 1825, el doctor Joaquín Infante anunció su regreso a la ciudad y ofreció de nuevo sus servicios como abogado en una oficina que abriría sus puertas al público el día 2 de enero en la esquina de la plaza de Santo Domingo. Otro colega suyo, Ignacio Muñoz, informó por esos días que instalaría su consultorio en la casa alta de la esquina del Tejadillo ${ }^{72}$.

A comienzos de 1823, el doctor Juan Francisco Arganil, bajo autorización del intendente del Magdalena, ofreció en la ciudad de Cartagena sus servicios como médico cirujano a un costo de 3 pesos diarios. Prometió aliviar toda suerte de enfermedades venéreas "con simples y sin mercurio", con el compromiso adicional de que aquellos que no fueran enteramente curados, les sería inmediatamente devuelto el dinero de la consulta73. No obstante, al cabo de dos años la municipalidad informó a través de este mismo medio periodístico que Arganil no había allegado los títulos que acreditaran su profesión y, de conformidad con el artículo $8^{\circ}$ del bando de policía, se le hizo saber que se abstuviera de ejercer su profesión so pena de sanciones en tanto que a los boticarios se les previno para que no le despacharan ningún tipo de recetas. El médico

\footnotetext{
70 “Aviso", en: Gaceta de Cartagena de Colombia, No. 225, diciembre 10 de 1825, p. 4.

71 “Aviso", en: Gaceta de Cartagena de Colombia, No. 226, diciembre 17 de 1825, p. 4.

72 "Aviso", en: Gaceta de Cartagena de Colombia, No. 227, diciembre 24 de 1825, p. 4.

73 “Aviso”, en: Gaceta de Cartagena de Colombia, No. 48, enero 11 de 1823, p. 204.
} 
protestó por esta decisión y, para ello, puso como prueba de su experiencia una de sus obras publicadas 74 .

Jorge López, antiguo farmaceuta de esta plaza, quien había emigrado en 1815 tras la arremetida de las fuerzas españolas de Reconquista al mando del general Pablo Morillo, volvió a mediados de 1822 a establecerse en su botica en la calle de San Agustín en el mismo lugar de antes. Para ello, debió ser apoyado económicamente por dos amigos pues había perdido todos sus haberes. Aseguró que ofrecería los medicamentos "más selectos en beneficio de la salud pública" 75 .

El cirujano dentista Enrique Fonbviale anunció a mediados de 1824 su arribo a la ciudad procedente de Jamaica para ejercer su profesión por poco tiempo. Estos fueron los principales servicios promocionados: "[...] limpia la dentadura, emploma y hace dientes artificiales que parecen naturales por un precio cómodo"76. Su consultorio lo ubicó en una casa al frente del cementerio de la catedral donde prometió atender todo el día aunque también abrió la posibilidad de visitar pacientes a domicilio.

En abril del año siguiente Pedro Julián Eudes de Gentilly, doctor de la universidad de París, ex cirujano mayor del ejército francés, cirujano oculista y comadrón77, quien además había aplicado sus conocimientos en Estados Unidos, expresó a través de un aviso de prensa su complacencia tras ser autorizado para ejercer su profesión en la ciudad de Cartagena. Su lugar de atención al público sería una casa ubicada en la plaza del Matadero en el horario de las doce del mediodía a las tres de la tarde ${ }^{78}$.

Después de ser liberada la ciudad de Cartagena, se registraron algunos progresos en cobertura de educación pública primaria y secundaria aun en medio de un ambiente hostil signado por la crisis económica, el déficit fiscal, la tensión político-militar y la

74 Roberto Cortázar (Comp.), Correspondencia dirigida al General Santander, Bogotá, Academia Colombiana de Historia, 1969, Vol. I, pp. 192-193.

75 “Aviso", en: Gaceta de Cartagena de Colombia, No. 17, junio 8 de 1822, p. 74.

76 “Otro", en: Gaceta de Cartagena de Colombia, No. 147, junio 5 de 1824, p. 616.

77 El comadrón era el que asistía a la mujer en su proceso de parto.

78 “Aviso”, en: Gaceta de Cartagena de Colombia, No. 192, abril 16 de 1825, p. 4. 
frágil estructura administrativa79. Reflejo de esos adelantos fueron precisamente algunos avisos de prensa en los que algunos maestros ofrecían sus destrezas pedagógicas.

A principios de 1824, en la Gaceta salió publicado un anuncio dirigido a los padres de familia de los pueblos de este departamento que, debido a la larga distancia, les resultaba difícil enviar sus hijos a la escuela de la ciudad de Cartagena, la capital. A ellos se les recordó que podían contar con una nueva opción que era la escuela de enseñanza mutua recién fundada en Mompós ${ }^{80}$.

Las autoridades municipales de Soledad publicaron en agosto de este mismo año un aviso en el cual informaban que el $1^{\circ}$ de septiembre siguiente enviarían una terna al intendente del departamento del Magdalena para el nombramiento del maestro. Como requisitos mínimos, el elegido debía enseñar a leer y escribir, y además transmitir los principios de ortografía, aritmética, dogmas religiosos, moral cívica y derechos del hombre en sociedad ${ }^{81}$.

No obstante, ante el escaso cubrimiento de la educación pública, una opción que adquirió fuerza por estos años fue la educación privada, dirigida especialmente a aquellos sectores con mayor capacidad económica. Allí las posibilidades de aprendizaje fueron más variadas por cuanto incluían música y lecciones de lenguas foráneas. Los maestros de estos centros de enseñanza, algunos de ellos extranjeros, no dudaron en divulgar sus servicios a través de la prensa local.

Así lo hizo el señor David Rosa, proveniente de la isla de Jamaica, quien promocionó a comienzos de 1825 un método efectivo y rápido para aprender a escribir en un mes y con "hermosa" letra. Su sistema lo creía aplicable incluso para personas de avanzada edad y aseguró tener unos costos moderados con la opción de enseñar en su casa o brindar el servicio a domicilio ${ }^{82}$. Semanas más tarde, el profesor Andrés Ballon promocionó la puesta en funcionamiento de una escuela de instrucción dirigida a niños de

79 Roger Pita Pico, "Educación, Patria y progreso: las escuelas de primeras letras en el Caribe colombiano, 1820-1828", en El Taller de la Historia Vol. 6, No. 6, Cartagena, Universidad de Cartagena, 2004, p. 372.

80 "Aviso a los pueblos", en: Gaceta de Cartagena de Colombia, No. 129, enero 31 de 1824, p. 538.

81 “Aviso", en: Gaceta de Cartagena de Colombia, No. 157, agosto 14 de 1824, p. 4.

82 “Aviso”, en: Gaceta de Cartagena de Colombia, No. 179, enero 15 de 1825, p. 4. 
ambos sexos, para lo cual puso de presente su comprobada experiencia docente en las ciudades de Charleston y Kingston durante más de dos décadas con satisfacciones para los padres y resultados exitosos en los estudiantes. El precio de la matrícula era de un peso y otro al fin de mes por saber leer, dos por escribir y tres por los conocimientos elementales de aritmética ${ }^{83}$.

Muy contadas también eran las instituciones de carácter privado para niñas, planteles que casi siempre respondían al interés de algunas extranjeras o damas prestantes de la ciudad. Madame Cavalier instaló a mediados de 1823 un establecimiento de educación para niñas con el lema de instruirlas en los rudimentos morales y en las pautas para ser una magnífica ama de casa y madre de familia ${ }^{84}$. Además, se les enseñaría a leer en francés y español, escribir, recitar algunas fábulas, y a tejer medias y encajes. Era opción de los padres que sus hijas recibieran clases de piano y música vocal, para lo cual debían sufragar una cuota adicional de 8 pesos.

Semanas atrás, para ser más exactos la noche del 29 de mayo, la profesora Cavalier había invitado a los cartageneros a un concierto y un baile con el fin de patentizar públicamente sus destrezas como maestra de música y de piano. Las boletas de entrada fueron vendidas en la casa de Mr. Eduardo Grisolls ${ }^{85}$.

\section{Testimonios de caridad}

Los actos de caridad ocuparon un lugar especial en los avisos de la Gaceta, con lo cual se hacía público el reconocimiento al donante, al tiempo que se dejaba constancia del agradecimiento de las autoridades o beneficiarios. De algún modo, este tipo de anuncios tenía una intención de estímulo para que muchos más ciudadanos se sumaran a estos actos de generosidad.

Tanto en la gaceta cartagenera como en otros periódicos que circulaban en esa misma época, solían aparecer donaciones de ciudadanos y religiosos para las arcas del naciente Estado, el cual estaba ávido de recursos para afrontar el proceso de recuperación

\footnotetext{
83 “Aviso", en: Gaceta de Cartagena de Colombia, No. 189, marzo 26 de 1825, p. 4.

84 “Aviso al público", en: Gaceta de Cartagena de Colombia, No. 94, julio 5 de 1823, p. 394.

85 “Aviso", en: Gaceta de Cartagena de Colombia, No. 82, mayo 24 de 1823, p. 346.
} 
económica, proteger la independencia política alcanzada e instituir las bases de su estructura administrativa.

Un ejemplo de esta clase de anuncios fue el que formalizó en septiembre de 1822 el ciudadano Vicente Polo, alcalde de la parroquia de Media Luna en la provincia de Santa Marta, quien cedió a favor del erario nacional lo que le correspondía por recolectar las contribuciones directas en el cantón, una decisión que fue valorada y exaltada en su momento por el intendente departamental ${ }^{86}$. A finales del siguiente año, el juez político del $4^{\circ}$ cantón de la provincia de Cartagena, Juan Antonio Oliver, expresó públicamente su voluntad de ceder al gobierno el $5 \%$ de lo recolectado por concepto de destilación y venta de aguardiente. El gobierno departamental agradeció expresamente este acto de generosidad ${ }^{8}$.

Dentro de las obras de caridad realizadas en estos años iniciales de vida republicana, suscitaba un sentimiento especial el socorro a los familiares de los combatientes que habían ofrendado sus vidas por la liberación de la República. En octubre de 1822, el ciudadano Manuel Marcelino Núñez anunció que en su casa ubicada en la calle de los Dolores procedería a distribuir un auxilio para las mujeres cartageneras que en el pasado sitio de la plaza hubiesen perdido a sus padres, esposos o hijos ${ }^{88}$.

En agosto del año siguiente, el ayuntamiento de Cartagena anunció que delegaría a dos de sus miembros para la recolección de un donativo dedicado a apaciguar la miseria de las viudas y huérfanos de los mártires de la Patria que lucharon en el combate naval del lago de Maracaibo ${ }^{89}$.

Para el homenaje tributado en 1825 en memoria de los soldados caídos en las batallas de Junín y Ayacucho que permitieron la liberación del Perú, la Intendencia de Cartagena dispuso que, en atención a las limitaciones del erario nacional, se optó entonces por convocar a los ciudadanos que quisieran dar testimonio público de su patriotismo para poder celebrar "dignamente" esos triunfos liderados por los generales Simón Bo-

86 "Rasgo de Patriotismo", en: Gaceta de Cartagena de Colombia, No. 33, septiembre 28 de 1822, p. 142.

87 “Aviso”, en: Gaceta de Cartagena de Colombia, No. 120, noviembre 29 de 1823, p. 502.

88 “Aviso", en: Gaceta de Cartagena de Colombia, No. 34, octubre 5 de 1822, p. 146.

89 “Patriotismo", en: Gaceta de Cartagena de Colombia, No. 106, agosto 23 de 1823, p. 442. 
lívar y Antonio José de Sucre. Las consignaciones las podían realizar en la sede de la imprenta del ciudadano Juan Antonio Calvo antes del 15 de junio con el fin de dar un margen de tiempo para los preparativos. Para imprimirle mayor difusión a esta convocatoria, fue publicado dos veces el respectivo aviso en las páginas de la prensa local9o.

A través de los anuncios del periódico también fue posible hacer seguimiento a las obras sociales que regularmente se desarrollaban en la ciudad. A finales de 1824, el colector de rentas de aguinaldos destinados al socorro de los pobres "vergonzantes" cobró 80 pesos que fueron entregados a los curas de las parroquias de la Catedral, la Santísima Trinidad y Santo Toribio para su respectiva distribución ${ }^{91}$.

\section{Avisos al servicio de los individuos}

Uno de los servicios sociales que cumplió la sección de avisos de prensa en el período objeto de este estudio era la alerta sobre objetos perdidos con la esperanza de que el periódico se convirtiera en un medio eficaz para transmitir en la ciudadanía esta información y ampliar así las posibilidades de recuperar lo extraviado. Dentro de la lista de objetos desaparecidos figuraban desde joyas y papeles de valor hasta esclavos escurridizos. En el anuncio se especificaban los detalles de estos elementos y se dejaba el nombre de una persona a manera de contacto. Como incentivo, solía proponerse una gratificación para los que proveyeran información certera o devolvieran lo perdido.

Según lo reportó la Gaceta, el jueves 31 de julio de 1823 se extravió una corona de plata dorada y un alfiler de diamantes con una piedra de zafiro en el centro. Quien encontrara estas joyas podía dirigirse a la botica del señor Brid donde sería "gratificado por su generosidad"92. En la calle que conducía de la esquina de San Agustín a la platería del señor Miguel Cardona se perdió en abril de 1825 un collar de perlas "muy hermoso con cuatro hilos". Aquella persona que suministrara pistas sólidas para hallar esta alhaja sería recompensado con dos onzas de oro93.

\footnotetext{
90 "Aviso al público", en: Gaceta de Cartagena de Colombia, No. 197, mayo 21 de 1825, p. 4; "Aviso al público”, en: Gaceta de Cartagena de Colombia, No. 199, junio 4 de 1825, p. 4.

${ }^{91}$ Gaceta de Cartagena de Colombia, No. 175, diciembre 18 de 1824, p. 4.

92 "Pérdidas", en: Gaceta de Cartagena de Colombia, No. 102, agosto 2 de 1823, p. 426.

93 “Otro", en: Gaceta de Cartagena de Colombia, No. 190, abril 2 de 1825, p. 4.
} 
Un esclavo de nombre José Antonio había sido enviado a las dos de la tarde del 18 de diciembre de 1824 por su amo Marcos Bernin a realizar una diligencia en la plaza pero inexplicablemente no volvió a la casa. A los interesados en ayudar a este desesperado propietario, se les prometió no solo una retribución pecuniaria sino también el reintegro de los costos que acarreara la labor de búsqueda94.

$\mathrm{Al}$ año siguiente, se reportó a través del periódico la desaparición de un documento de valor, razón por la cual hubo necesidad de hacer advertencias precisas a los que pudieran encontrarlo:

Se ha perdido o traspapelado un libramiento girado por el Sr. Guillermo Linch contra el Sr. Santiago Brusch y a favor de los que suscriben el que está aceptado por dicho Sr. Brusch en Cartagena a 21 de enero de 1825 y pagadero a cuatro meses de la fecha en cantidad de seis mil ochocientos ochenta y seis pesos. Se avisa que el documento no está endosado a persona alguna y es de ningún valor ni negociable en ninguna manera. Y para el efecto está avisado el Sr. Brusch no pague nada a ninguna otra persona que a los mismos interesados 95 .

Un asunto de marcada importancia desde los tiempos del dominio hispánico era la honra y el buen nombre. Por eso, cuando un individuo se veía perjudicado por este asunto, emprendía todos los esfuerzos posibles con tal de reivindicar su reputación e integridad moral. Veamos un ejemplo concreto a través del siguiente aviso difundido en la edición No. 84 de la Gaceta:

Jorge Krochmannl por la presente hago saber que no tengo ninguna relación con el Sr. Jaime Toose. Hago esta declaración para desengañar a los individuos que pudieren creer que el expresado tuviese demandas contra mí. Cartagena. 31 de mayo de $1823^{96}$.

Severo Courtois informó en enero de 1825 a la comunidad cartagenera de su viaje a Bogotá para seguir en los tribunales de esa capital las demandas interpuestas por Ma-

\footnotetext{
94 “Aviso”, en: Gaceta de Cartagena de Colombia, No. 124, diciembre 27 de 1824, p. 518.

95 “Aviso", en: Gaceta de Cartagena de Colombia, No. 187, marzo 12 de 1825, p. 4.

96 “Aviso”, en: Gaceta de Cartagena de Colombia, No. 84, mayo 31 de 1823, p. 354.
} 
teo Lavignac. Mientras resolvía estos asuntos judiciales, dejó en Cartagena a su apoderado, el señor Pontier, con quien había que saldar todos los negocios pendientes 97 . Al mes siguiente, el empresario antioqueño Francisco Montoya colocó un aviso de prensa en el que informaba haber llegado a Cartagena procedente de Inglaterra. En razón a algunos ataques que él y su socio Manuel Antonio Arrubla habían recibido respecto a su conducta como negociadores de un préstamo oficial, pidió a los que tuviesen imputaciones que las hicieran conocer en Bogotá donde estarían prestos a despejar cualquier duda. Solicitó encarecidamente hacer uso de esta vía legal y no del "charlatanismo y vanas declaraciones" 98 .

El anuncio de acontecimientos importantes en el ciclo de vida de las personas, como los bautizos, los matrimonios y los fallecimientos, es un tema que ocupa en la actual sociedad moderna un lugar destacado en la sección de los avisos de periódicos. No sucedía lo mismo para el período objeto de este estudio, cuando tal tipo de avisos eran más bien escasos.

Un anuncio de prensa publicado en la Gaceta dio cuenta del matrimonio celebrado el 31 de octubre de 1824 en la sede del consulado británico en Cartagena entre el comerciante de la ciudad de Santo Domingo J. Toose y Carolina Eliza, hija de un mercader de Kingston. La ceremonia nupcial se hizo en presencia del cónsul Eduardo Watts y la novia fue entregada por el cónsul norteamericano J. M. Macpherson99.

Sobre decesos solo existe un registro en las ediciones consultadas, se trata de un aviso en el que el cónsul de Estados Unidos en Cartagena informó al público de la muerte de su compatriota Carlos Hildebrand, ahogado en su viaje marítimo a la ciudad de Santa Marta ${ }^{100}$.

\section{A manera de conclusión}

\footnotetext{
97 “Aviso", en: Gaceta de Cartagena de Colombia, No. 181, enero 29 de 1825, p. 4. 98 “Aviso", en: Gaceta de Cartagena de Colombia, No. 184, febrero 19 de 1825, p. 4.

99 Gaceta de Cartagena de Colombia, No. 171, noviembre 20 de 1824, p. 4.

100 “Aviso”, en: Gaceta de Cartagena de Colombia, No. 198, mayo 28 de 1825, p. 4.
} 
Pese al limitado alcance que pudiera tener la circulación de los periódicos a un reducido grupo de personas letradas, no hay duda de que los anuncios clasificados publicados en estos medios impresos se convirtieron en un nuevo espacio de difusión para aquellos interesados en llevar un mensaje a la comunidad, ya fuera a manera de información, servicio social o promoción de oportunidades económicas.

Era evidente además que la mayoría de autores y destinatarios de esta primera generación de avisos de prensa eran ciudadanos pertenecientes a los sectores que ostentaban el poder social, político y económico en la ciudad de Cartagena. Sin embargo, el incremento del número de periódicos y las crecientes opciones de educación pública promovidas por el gobierno republicano, significarían nuevas oportunidades para que paulatinamente los avisos fueran logrando un alcance masivo en la sociedad.

A nivel oficial, el gobierno y el estamento militar fueron los que más usaron este tipo de avisos. Sorprende que el estamento eclesiástico no recurriera a este espacio de comunicación, quizás porque ellos seguían contando con uno de los canales más efectivos para llegarle a la población desde tiempos coloniales: las misas dominicales.

El contenido mismo de los avisos publicados en estos primeros años de vida republicana reflejaron de distintas formas los efectos de las guerras de Independencia y el periodo de transición al sistema republicano que esa etapa de conflicto político y militar provocó. Es así como puede observarse en estos mensajes el afán por la recuperación económica y la actitud solidaria tras los estragos de estas guerras que se habían ensañado sobre la ciudad.

De igual modo, quedó demostrado a través de los avisos de prensa el carácter cosmopolita de Cartagena en su calidad de puerto marítimo, lo cual se vio reflejado en la intensa vida social y económica de los extranjeros que allí tenían asiento.

\section{Bibliografía}

\section{Prensa}


Gaceta de Cartagena de Colombia, Cartagena, Imprenta del Gobierno por Juan Antonio Calvo, 1822-1825.

\section{Fuentes primarias impresas}

Cortázar, Roberto (Comp.), Correspondencia dirigida al General Santander, Bogotá, Academia Colombiana de Historia, 1969, Vol. I.

\section{Fuentes secundarias}

Cubillos Vergara, María Carolina, "El difícil tránsito hacia la modernidad: la prensa en Colombia”, en Folios, No. 27, Medellín, Universidad de Antioquia, 2012, pp. 4765.

Jaramillo Uribe, Jaime, Ensayos de Historia Social, Bogotá, Tercer Mundo-Uniandes, 1987.

Pita Pico, Roger, "Educación, Patria y progreso: las escuelas de primeras letras en el Caribe colombiano, 1820-1828", en El Taller de la Historia, Vol. 6, No. 6, Cartagena, Universidad de Cartagena, 2004, pp. 346-376.

Pita Pico, Roger, "El impacto de las guerras de Independencia en las haciendas esclavistas de la provincia de Cartagena", en Huellas, Vol. 98, Barranquilla, Revista de la Universidad del Norte, julio-diciembre de 2015, pp. 4-16.

Pita Pico, Roger, "La manumisión en la costa Caribe colombiana durante el proceso de Independencia: vicisitudes de una ilusión aplazada, 1810-1825", en: Historia Caribe, Vol. VIII, No. 22, Barranquilla, Universidad del Atlántico, enero-junio de 2013, pp. 43-73.

Polo Barros, Nataly, La prensa en Cartagena: algunos aspectos sobre Nación 18201840, Cartagena, Tesis de Grado del programa de Historia de la Universidad de Cartagena, 2015.

Silva Olarte, Renán, "El periodismo y la prensa a finales del siglo XVIII y principios del siglo XIX en Colombia", Cali, Documento CIDSE Universidad del Valle, 2003, pp. 14-20.

Sourdís de Najera, Adelaida, "Cartagena de Indias, visión panorámica", en Credencial Historia, No. 222, Bogotá, Revista Credencial, junio de 2008, pp. 1-6.

Therrien, Monika, "El espacio urbano de Cartagena en la Colonia”, en Historia Crítica, No. 2, Bogotá, Universidad de Los Andes, julio-diciembre de 1989, pp. 111-115. 
Tovar Pinzón, Hermes, "La lenta ruptura con el pasado colonial”, en Historia económica de Colombia, Bogotá, Tercer Mundo Editores, $4^{\text {a }}$ edición, 1994. 